\title{
Generating an Audio and Text for Indian Sign Language
}

\author{
Renjitha.R, Rubashree.D, Priya.V, Preetha.C
}

\begin{abstract}
Every normal people have the ability to observe and respond to the environment. Nearby are several unlucky persons who doesn't encompass this principal blessing. Deaf and Dumb people have to communicate with normal people, it's a challenging task. Sign Language is designed for deaf and dump people to convey message to the society. Sign Language Recognition is a technology which is used to identify human gestures with the help of Arduino uno. Gesture recognition based on the corresponding gesture symbol produces an audio \& text output. The flex sensor is used to recognize the hand gestures. Recognized gesture is transferred to the Arduino uno and the output is generated. By using these techniques we can implement an efficient audio \& text output for physically challenged people. Our technology consists of glove which will be worn by dumb people to communicate with normal people. The proposed prototype could also serve as an intermediate between deaf and dump people and normal people in everyday life such as bank or post office. The output will be displayed using LCD and also produces a speech signal.
\end{abstract}

Keywords: Audio amplifier, Arduino uno, Flex sensor, LCD ,Sign language, Speaker.

\section{INTRODUCTION}

The gesture is one of the non verbal and non vocal communication forms in which atypical parts of bodies are used to arise kind of evocative sentence or message. The gesture is like a movement of body and it can be expressed using hand, face, head and lips to convey unique ideas. The gesture recognition is an technique in gesture interpretation to convey the thoughts by dumb people. Gestures agree folks to convey an array of emotions and opinion through body language without the practice of language as they speak. This study is allied to dumb people which is amiable in converting their gestures into speech signals. This developed system gives an easy way for dumb people to connect with any habitual people. One article about dumb people have the ability to read and hear like normal people but can't convey as their wish. Therefore this is a challenging assignment for them. In this system gesture converted into an audio signal and it is easily understandable by habitual people.

Revised Manuscript Received on February 05, 2020.

* Correspondence Author

Renjitha.R*, Assistant professor, Sri Krishna College Of Technology, Tamilnadu.

Rubashree.D, B.E, Electronics and Communication Engineering, Sri Krishna college of Technology, Coimbatore.

Priya.V, B.E, Electronics and Communication Engineering, Sri Krishna college of Technology, Coimbatore.

Preetha.C, B.E, Electronics and Communication Engineering, Sri Krishna college of Technology, Coimbatore.

(C) The Authors. Published by Blue Eyes Intelligence Engineering and Sciences Publication (BEIESP). This is an open access article under the CC BY-NC-ND license (http://creativecommons.org/licenses/by-nc-nd/4.0/)
Because habitual people doesn't have any knowledge about sign language. This study includes Indian sign language for Indian folks.

\section{LITERATURE SURVEY}

By using 10 megapixel web camera for the capturing the gesture. Twelve characters was unable to recognize because there should be a limitation of 1 meter distance between camera and human[1]. The success rate was reduced because of the complex background and lighting. It can be improved through Edge Oriented Histogram[6]. The system needed an additional complex circuit other than the necessary circuit for the function of analyzing the finger and display of character[2].To determine the exact image of the gesture a sensor and a web cam both has been used. To give the effective result the leap motion sensor is used[3].Usage of machine learning algorithm for the gesture recognition have the conditions such as the user should be in a finite distance from the camera, the gesture should be performed by bare hands[4]. Kinetic sensor used for the capture of signer who wore a black wristband. The deletion error of sign occur when the sensor failed to analyse the sign that has been performed[5]. Recognition using Kinect also include hidden Markov models for observing the continuous density. It has high success rate for training new gestures by demonstrating in front of camera[12]. Human Computer Interaction(HCI) has made the user interface to helps in capture the hand gestures in an effective way. This method acquire the data from both data gloves and vision based[8]. In static mode, the feedforward and recurrent neural network architecture also used for recognition. The extraction of gesture by image processing is used in developing the neural network architecture[13]. The language recognition obtained from Histograms of Oriented Gradients (HOG) which is learnt from One-Versus-All Support Vector Machine (SVM). By usage of image based technology various visual descriptors are included to a build an alphabet recognizer[14].

\section{HARDWRE DESCRIPTION}

A. Flex sensor: To measure the amount of defection or bend the flex sensor is used. It is manufactured from plastic and carbon. In the flex sensor, carbon surface is mounted on the plastic strip. The sensors resistance is based on the bending of plastic strip. Flex sensor has two types of sizes, such as 2.2-inch and 4.5-inch. $\mathrm{p} 1$ and $\mathrm{p} 2$ are two terminals present in this sensor. It doesn't have positive and negative terminal. To remain active the flex sensor need a 5V supply. 
The pin P1 is connected to positive terminal of power supply and pin P2 is connected to ground pin of power supply. Normally, the linear resistance of flex sensor is $25 \mathrm{~K} \Omega$. The tolerance range is about $\pm 30 \%$.

Table.1 Threshold values of Resistance sensor for 2.2", and 4.2"' long

\begin{tabular}{|l|c|c|c|c|c|c|}
\hline \multirow{2}{*}{ Sensor } & \multicolumn{6}{|c|}{ Degree of bend } \\
\cline { 2 - 7 } & $0^{\circ}$ & $30^{\circ}$ & $60^{\circ}$ & $90^{\circ}$ & $120^{\circ}$ & $150^{\circ}$ \\
\hline $\begin{array}{l}\text { Resistance } \\
\text { 2.2', (V) }\end{array}$ & 1.79 & 1.93 & 2.50 & 3.04 & 3.12 & 3.22 \\
\hline $\begin{array}{l}\text { Resistance } \\
\text { 4.2',(V) }\end{array}$ & 1.40 & 1.65 & 2.02 & 2.15 & 2.21 & 2.32 \\
\hline
\end{tabular}

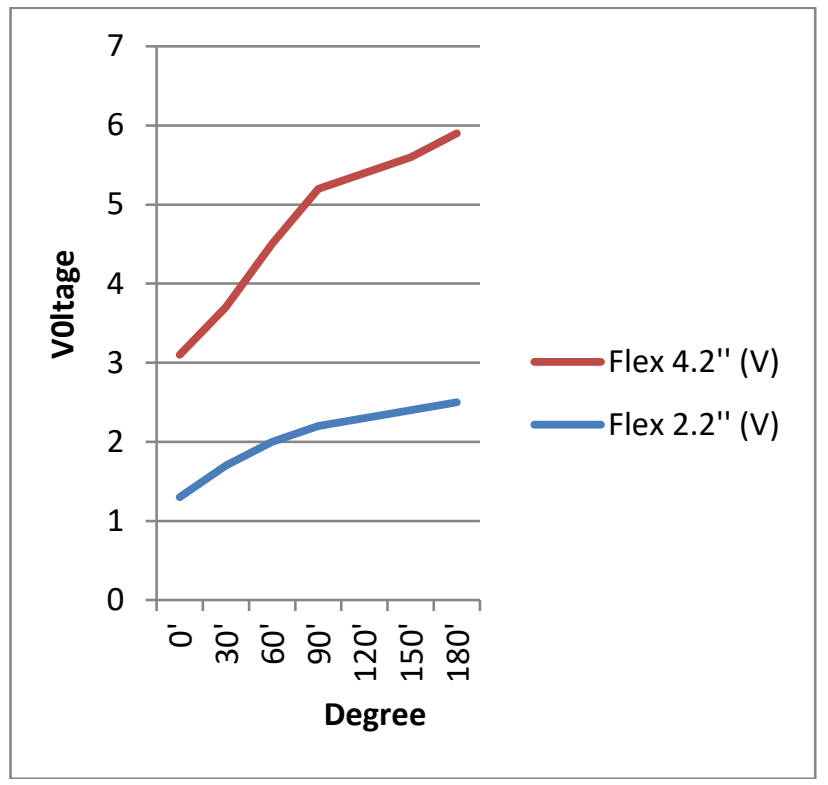
Fig.1 Graph for Resistance sensor values for various
bends of finger

B.Arduino Mega 2560: To measure the amount of defection or bend the flex sensor is used. It is manufactured from plastic and carbon. In the flex sensor, carbon surface is mounted on the plastic strip. The sensors resistance is based on the bending of plastic strip. Flex sensor has two types of sizes, such as 2.2-inch and 4.5-inch. p1 and p2 are two terminals present in this sensor. It doesn't have positive and negative terminal. To remain active the flex sensor need a $5 \mathrm{~V}$ supply. The pin P1 is connected to positive terminal of power supply and pin P2 is connected to ground pin of power supply. Normally, the linear resistance of flex sensor is $25 \mathrm{~K} \Omega$. The tolerance range is about $\pm 30 \%$.

C.Audio amplifier: Audio amplifier is used to strengthen the low signal without altering the data signal. Amplifier contains IC which consist of 21 transistors and it has simple design. IC consists of 12 pins where pin 1 and 4 are connected to power supply and pin 9 and 10 are connected to ground. And also pin 8 is connected to input of the Arduino and pin 12 is connected to output of the Arduino. Then speaker is coupled to condenser. The volume of the signal is depends on IC. The output can be reached upto 7W. Through this sound can be varied.

\section{SYSTEM OVERVIEW}

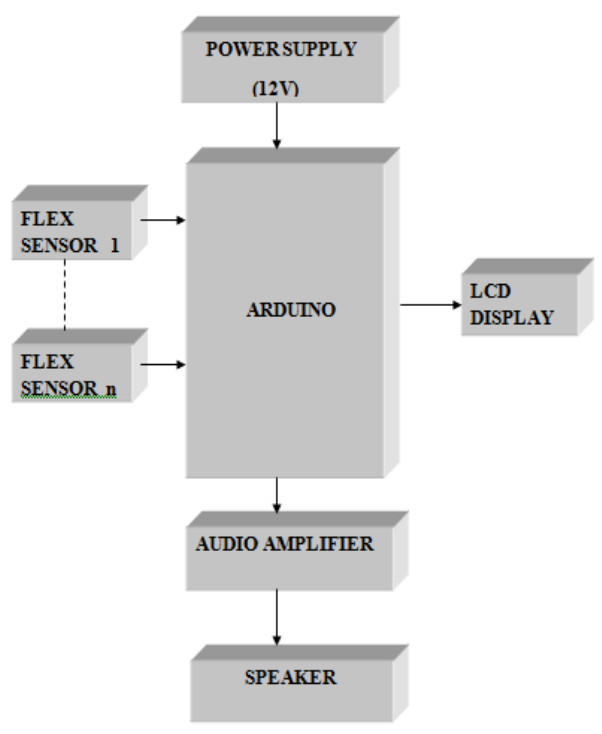

Fig.2 Block diagram

This block diagram consist of ten flex sensor, a controller, LCD display and audio amplifier as shown in the fig. The resistance is obtained for the performed gesture. Here the force is converted into resistance. The Analog signal from the sensor is pass to Arduino. The signal will be given to the Analog pins of Arduino. According to the program fed to the controller the output will be generated. The Analog signal is changed into digital signal for the LCD display. The text output is generated. The corresponding Analog signal of the output is send to audio amplifier. The fed signal is weak so it is amplified using amplifier. Finally the audio output is played through speaker.

\section{SYSTEM FLOW}



Fig.3 Flow chart of the proposed method

The flow of the system is shown in the fig.3. It describes how this model works. The gesture symbol performed by dumb people is sensed by the sensor. The sensor input is obtained. If it recognize the correct gesture symbol, it generate the corresponding output. If it couldn't recognize the gesture, it will wait for another gesture. 
Each and Every gesture have some range of values. The output will be both audio and text.

\section{EXPERIMENTAL RESULTS}

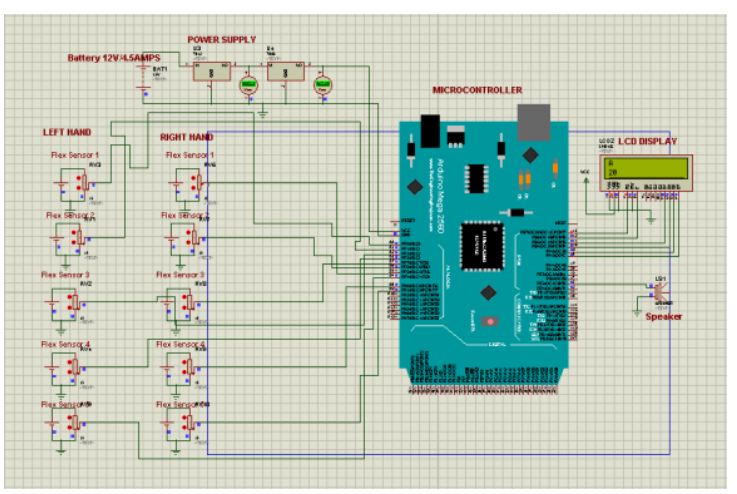

Fig.4 Result 1 of the system

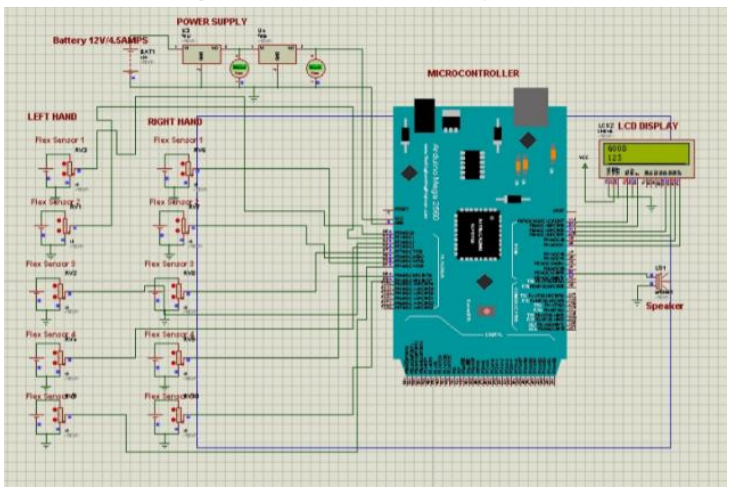

Fig.5 Result 2 of the system

The obtained result uses the general formula of voltage divider to calculate the resistance value of the gesture shown in equation(1).

$$
V=\frac{R}{(R+5)} * 5
$$

Where R- Resistance.

Table.2 Success Rate of the system for some results

\begin{tabular}{|c|c|c|}
\hline S.No & Sign & Success Rate \\
\hline 1. & $\mathrm{~A}$ & $100 \%$ \\
\hline 2. & $\mathrm{P}$ & $96 \%$ \\
\hline 3. & $\mathrm{Z}$ & $87.5 \%$ \\
\hline 4. & Good & $100 \%$ \\
\hline 5. & Sand & $93 \%$ \\
\hline 6. & Safe & $87.5 \%$ \\
\hline 7. & Time & $90 \%$ \\
\hline 8. & Working & $87.5 \%$ \\
\hline 9. & Doors & $100 \%$ \\
\hline 10. & Right & $98 \%$ \\
\hline
\end{tabular}

\section{SUMMARY}

Sign languages exercise discrete kinds of expression for communication in day to day life. Particularly, it is one of the modes of convey for dumb people. Thus, it provides a substitute for the discourse between dumb and normal people. Gesture language acknowledgement plays an significant role in a variety of fields such as engineering, medical and also makes an impact on the individual civilization. A sign language appreciation system can provide possibility for the dumb people to speak with natural folks without the need of an interpreter. sign languages are well-designed languages with language rules and grammar distinctive from oral languages . Actually, here is a differentiation between verbal language and sign language in which verbal language make use of words continuously, where as indicator language make use of body movements in temporal space. This examining operation is implemented from each performed by two employee gestures for sign language recall purpose. The gesture can be performed by one or two hands. Divergence occur between one hand gesture and two hand gestures. In this system for recognizing the gesture we use two hands. Various places of India use Indian Sign language as official language for dumb people. Its creation is based on the British Sign language and American Sign Language. Two types for recognizing sign language such as static and dynamic. Here we use static sign language for recognizing gestures. This produces a precise result.

\section{CONCLUSION}

The sign language used by dump people cannot be easily understood by normal people. The audio output is also help the blind to hear the conversation as well as normal. This area of study remains active and it is noticeable improvement in computing, sensor devices, materials and the glove devices are cheaper and more powerful. The same technique can be used in various sign language.In future we promote this model has a wireless system for easy communication and easy access. This method can also be designed in dynamic mode also. Further it can be implemented using whole jacket fitted with sensors for the use of paralyzed people by body movement. This system able to extensive with robots for the cooperation between human actions.

\section{REFERENCE}

1. S.Shivashankara and S.Srinath, "American sign language recognition system: an optimal approach,” International Journal of Image, Graphics and Signal Processing, vol-10, pp-18-30,2018.

2. Hanine El Hayek, Jessica Nacouzi, Abdallah kassem, Mustapha Hamad and Sami El-Murr, "Sign to Letter Translator System using a Hand Glove,” Internatinal conference on e-technologies abd networks for development, 2014

3. Rajesh George Rajan, M Judith Leo," A Comprehensive Analysis on Sign Language Recognition System”, International Journal of Recent Technology and Engineering,vol-7,2019.

4. Paulo Trigueiros,Fernando Ribeiro, and Luís Paulo Reis3," Visionbased Portuguese Sign Language Recognition System",Machine Learning,2014.

5. Hee-Deok Yang, "Sign Language Recognition with the Kinect Sensor Based on Conditional Random Fields", Sensors 2015 ,15, 135-147.

6. Jayshree R. Pansare, Maya Ingle, "Vision-Based Approach for American Sign Language Recognition Using Edge Orientation Histogram", International Conference on Image, Vision and Computing, pp.86-90, 2016.

7. Lahamy, H.; Lichti, D.D. "Towards real-time and rotation-invariant American Sign Language alphabet recognition using a range camera". Sensors 2012, 12, 14416-14441.

8. Shivashankara S, Srinath S, "A Review on Vision Based American Sign Language Recognition, its Techniques, and Outcomes", 7th IEEE International Conference on Communication Systems and Network Technologies (CSNT-2017), pp.293-299, 2017. 


\section{Generating an Audio and Text for Indian Sign Language}

9. Geetha M, Rohit Menon, Suranya Jayan, Raju James, Janardhan G.V.V, "Gesture Recognition for American Sign Language with Polygon Approximation", IEEE International Conference on Technology for Education, pp.241-245, 2011.

10. Murthy, G.R.S. and R.S. Jadon, "A Review of Vision Based Hand Gestures Recognition". International Journal of Information Technology and Knowledge Management, 2009. 2(2): p. 405-410.

11. Trigueiros, P., F. Ribeiro, and L.P. Reis. "A comparison of machine learning algorithms applied to hand gesture recognition". in 7th Iberian Conference on Information Systems and Technologies. 2012. Madrid, Spain.

12. Lang, S., M. Block, and R. Rojas, "Sign language recognition using kinect", 2012: Zakopane. p. 394-402.

13. M. Maraqa and R. Abu-Zaiter, "Recognition of Arabic sign language (ARSL) using recurrent neural networks," in Applications of Digital Information and Web Technologies, 2008. ICADIWT 2008. First International Conference on the. IEEE, 2008, pp. 478-481.

14. R. Alzohairi, R. Alghonaim, W. Alshehri, S. Aloqeely, M. Alzaidan, O.Bchir, "Image based arabic sign language recognition"International Journal of Advanced Computer Science and Applications, Vol. 9, No. 3, 2018.

15. Zafrulla, Z.; Brashear, H.; Starner, T.; Hamilton, H.; Presti, P."American sign language recognition with the kinect". In Proceedings of the International Conference on Multimodal Interfaces, Alicante, Spain, 14-18 November 2011; pp. 279-286.

\section{AUTHORS PROFILE}

Renjitha.R has completed her B.E degree in Electronics and Communication from CMS College of Engineering and Technology, Coimbatore. She received her M.E degree from Sri Krishna College of Engineering and Technology, Coimbatore. She is working as assistant professor at skct. She published "Cellular call equalization

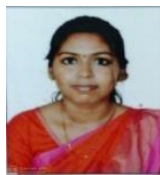
using discrete normalization technique" journal in 2018. She attended the conferences "Efficient date collection scheme for manet","Voice amplified equalization in cellular conference call". Her area of interest is Networking.

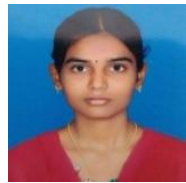

Rubashree.D is a student of B.E in Electronics and Communication Engineering at Sri Krishna college of Technology, Coimbatore . Her journal itself describes her involvement in embedded system. She is also interested in Robotics.

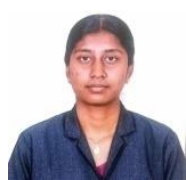

Priya.V completed her higher secondary education from Malco Vidyalaya Matric Hr.Sec.School,Salem. She is currently pursuing her B.E in Electronics and Communication Engineering from Sri Krishna college of Technology, Coimbatore. Her interest in embedded system has paved a way for her research in this field.

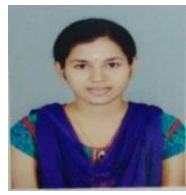

Preetha.C has completed her Higher secondary from Bannari Amman Vidhya Niketan Matric Hr.Sec.School. She is currently pursuing her B.E in Electronics and Communication Engineering from Sri Krishna college of technology, Coimbatore. Her area of interest is embedded system and automotive electronics. 